\title{
PI 0-I3. Increased production of alpha-defensins I-3 by dendritic cells in HIV-infected individuals is associated with a slower disease progression rate
}

\author{
M Rodriguez-Garcia*, N Climent, H Oliva, C Rovira, L Miralles, A Leon, \\ J Gatell, F Garcia and T Gallart
}

Address: Immunology, Hospital Clinic, Barcelona, Spain

* Corresponding author

from AIDS Vaccine 2009

Paris, France. 19-22 October 2009

Published: 22 October 2009

Retrovirology 2009, 6(Suppl 3):PI44 doi:10.I I86/I742-4690-6-S3-PI44

This abstract is available from: http://www.retrovirology.com/content/6/S3/PI44

(c) 2009 Rodriguez-Garcia et al; licensee BioMed Central Ltd.

\section{Background}

Defensins are natural peptides with potent anti-HIV activity. In humans two subfamilies exist, $\alpha$ - and $\beta$-defensins. $\alpha$-Defensins $1-3$ are mainly secreted by neutrophils, although other leukocytes also produce them. Besides their direct antimicrobial effect, $\alpha$-defensins $1-3$ also exert immunomodulory activities, chemoattracting leukocytes and inducing cytokines and chemokines production. We previously demonstrated that immature monocytederived dendritic cells (MDDC produce and secrete $\alpha$ defensins 1-3 and that these defensins are able to modulate de maturation and differentiation of dendritic cells.

\section{Methods}

MDDC were generated in vitro from peripheral blood from volunteer healthy controls (HC) and HIV-infected patients, including elite controllers, viremic controllers, untreated viremic noncontrollers and treated patients. To determine $\alpha$-defensins $1-3$ production, culture supernatants were analyzed by ELISA and cells by real time RTPCR for mRNA expression.

\section{Results}

Immature MDDC from HIV-infected patients secreted significantly higher levels of $\alpha$-defensins $1-3$ than HC ( $\mathrm{p}<$ $0.0001)$. Within the HIV-infected group, this production was statistically increased in untrated HIV-infected controllers ( $\mathrm{p}<0.0001$ vs HC) while in untreated viremic and treated HIV-infected patients the production was not sig- nificantly increased. The levels of $\alpha$-defensins 1-3 secreted by immature MDDC positively correlated with CD4 T cell counts in the controllers group $(\mathrm{r}=0.59 ; \mathrm{p}<$ $0.009)$, but not in viremic noncontrollers and treated patients. No differences were observed in plasmatic $\alpha$ defensins 1-3 levels. HIV-infected patients with higher $\alpha$ defensins 1-3 secretion by immature MDDC showed a slower disease progression, measured as no decrease in the number of CD4+ T-cells below 350 cell $/ \mathrm{mm} 3$ [HR = 8.9 (CI 1.2-65); $\mathrm{p}<0.035$ ], fewer increase in plasmatic viral load $[\mathrm{HR}=2.67$ (CI 1.05-6.74; $\mathrm{p}<0.04]$ and no initiation of treatment [HR $=10$ (CI 1.02-98.2); $\mathrm{p}<0.05$ ] along time.

\section{Conclusion}

Immature MDDC from HIV-infected patients who spontaneously control the infection produced higher levels of $\alpha$-defensins $1-3$. This increased production of alphadefensins 1-3 was associated with a slower disease progression. 